\title{
A chegada da Cultura Caubói no Acre, Brasil
}

\author{
The arrival of the Cowboy Culture in Acre, Brazil
}

\author{
Dr Jeffrey Hoelle \\ University of California, Santa Barbara, United States \\ hoelle@anth.ucsb.edu
}

\section{Resumo}

O presente artigo trata de aspectos da cultura rural/urbana no Acre, desenvolvidos durante o processo recente de reocupação da região, trazidos por diferentes grupos migrantes. Tomando o gado bovino, o boi, como elemento a partir do qual se traçam análises da reorganização da vida nesse novo local, recriando com cores próprias a chamada cultura country, com roupas, músicas, danças, apropriada por pessoas, geralmente jovens, sem relações com o universo rural e, por outro lado, o cotidiano dos pequenos proprietários rurais, marcado pela dura rotina de trabalho, poucos recursos e sofrendo as atrações do modo de vida urbano. Nesses cenários onde o boi vai de anima de estimação a commodity, reconstroem-se com cores próprias, as influências trazidas de outros pontos do país que pautam a construção de relações sociais e econômicas.

Palavras-chave: Country; Boi; Acre; Cultura; Caubói.

\begin{abstract}
This article deals with aspects of rural/urban culture in Acre, developed during the recent process of the reoccupation of the region, brought by different migrant groups. Taking the cattle, the ox, as an element from which analyzes of the reorganization of life in this new place is traced, recreating from the local peculiarities the so-called country culture, with clothes, music, dances, appropriated by people, usually young people without relations with the rural universe and, on the other hand, the daily life of small rural landowners, marked by the hard work routine, few resources and suffering the attractions of the urban way of life. In these scenarios where the ox goes from pet to commodity, the influences brought from other parts of the country that guide the construction of social and economic relations are reconstructed with their colours.
\end{abstract}

Keywords: Country; Ox; Acre; Culture; Cowboy.

\section{INTRODUÇÃO}

Jatobá, Luanna, e Espimar Rocha viviam nas florestas de São João, seringal dentro da Reserva Extrativista Chico Mendes, no estado do Acre. Quando eu os conheci em 2007, eles não tinham gado, mas quando retornei no ano seguinte, eles haviam adquirido um touro branco. Ao longo do tempo pude perceber a afeição que eles nutriam por aquele touro chamado "Tchoa". O animal quase sempre enfiava sua cabeça pela janela da cozinha procurando por sal, o qual ele lambia com gosto de nossas mãos ou de uma pequena pilha nos degraus da frente da casa (figura1). Assim que ele notava alguém saindo da floresta ele caminhava e se prostrava até que esfregassem suas costas manchadas de branco e preto, sua cabeça e seu papo. Quando Espimar derrubava as laranjas da árvore, Tchoa estava sempre ao seu lado esperando para pegar um pedaço com sua língua áspera ou engoli-la como um todo. 


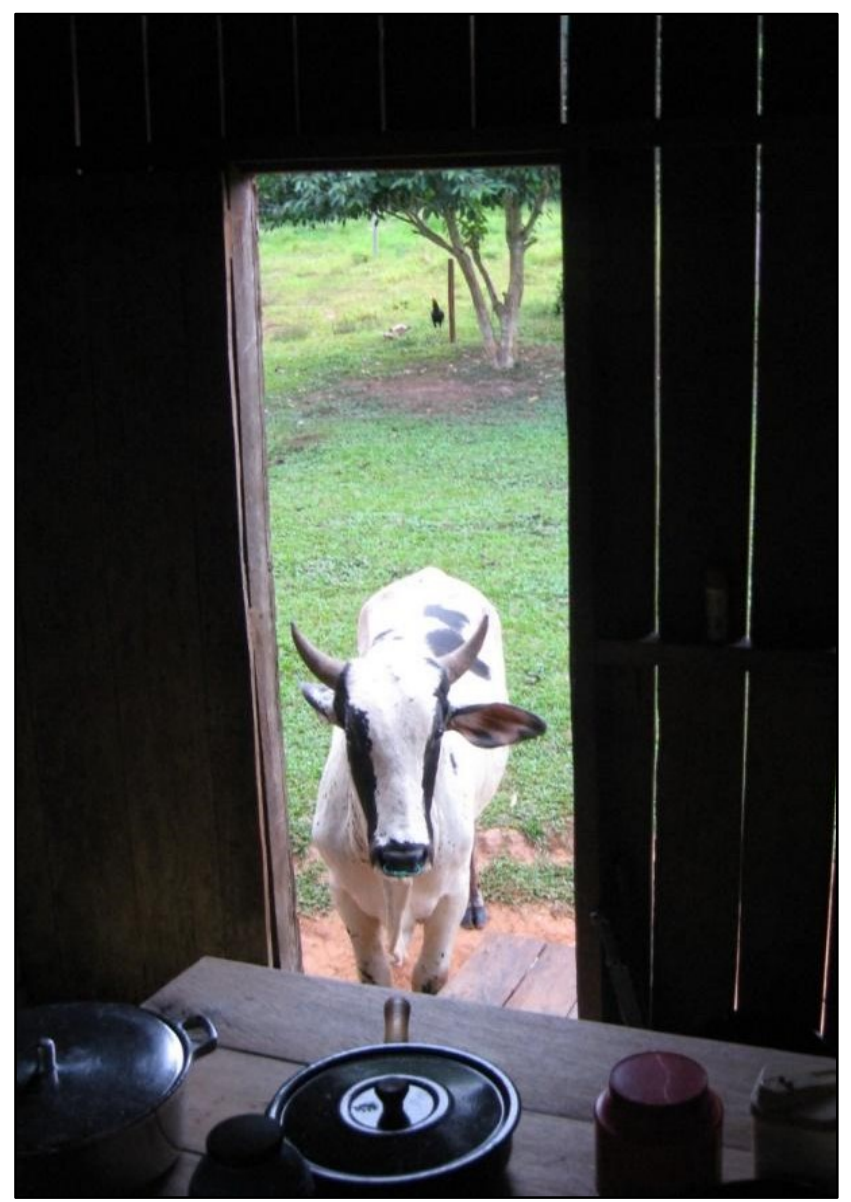

Figura 1 - O touro Tchoa na porta da família Rocha.

A família adorava Tchoa, mas Jatobá me disse que sua aquisição tinha sido feita mais em relação a sua utilidade. Em 2009 eles colocaram uma argola feita de um velho fio de arame isolado no nariz de Tchoa facilitando acorrentá-lo e puxá-lo. Espimar esticou uma corda pela argola improvisando uma rédea e muitas vezes cavalgava Tchoa para a escola. Em 2010, com a ajuda de um touro vizinho, Tchoa já estava puxando carroças que traziam borracha, castanhas do Brasil, e outros produtos até o ponto de coleta. Desse lugar em diante, os produtos saiam da floresta pelo ramal lateral e daí para a já asfaltada estrada BR-317 que levava a cidade de Brasiléia e depois Rio Branco.

Ao longo de todo esse percurso, caubóis trabalham nas fazendas. Eles vestem couro, comem carne e comemoram essa visão da vida rural nos rodeios. Mesmo não tendo nenhuma ligação com a vida rural, existem pessoas na cidade que também se vestem como caubóis. Sorocaba, por exemplo, vivia em Rio Branco. Ele estudava direito ambiental e apesar de "ser apaixonado pela vida country", não tinha terra nem gado. Em 2009 ele comprou um ótimo cavalo e o estreou na cavalgada do ano seguinte, em Rio Branco. A cavalgada é formada por grupos separados de cavaleiros chamados de comitivas - remetendo as picadas de antigamente do centrosul do Brasil. A comitiva de Sorocaba era financiada pelo "Cowboys Ranch", uma loja de roupas que vendia modelos country, selas e até latas de pó de tabaco Copenhagen. 
Cada comitiva seguia um caminhão que puxava um trailer duplo coberto com palheiras e adornado com fardos de feno. O veículo que ia na frente do grupo dos "Cowboys Ranch" tinha um palco no teto onde um homem vestido com chapéu caubói preto e jaqueta de couro cantava em alto som músicas sertaneja e covers de hits americanos. Além disso, cada trailer da cavalgada estava carregado de cerveja gelada, caixas de som ressoando música country e uma churrasqueira lotada de espetinhos de carne e linguiça (figura 2). Motoristas se aglomeravam perto do trailer em busca de refrescos ao longo do trecho de seis horas entre o rio Acre e o Parque de Exposições; a chegada da comitiva marcava o início da festa da Expo-Acre.

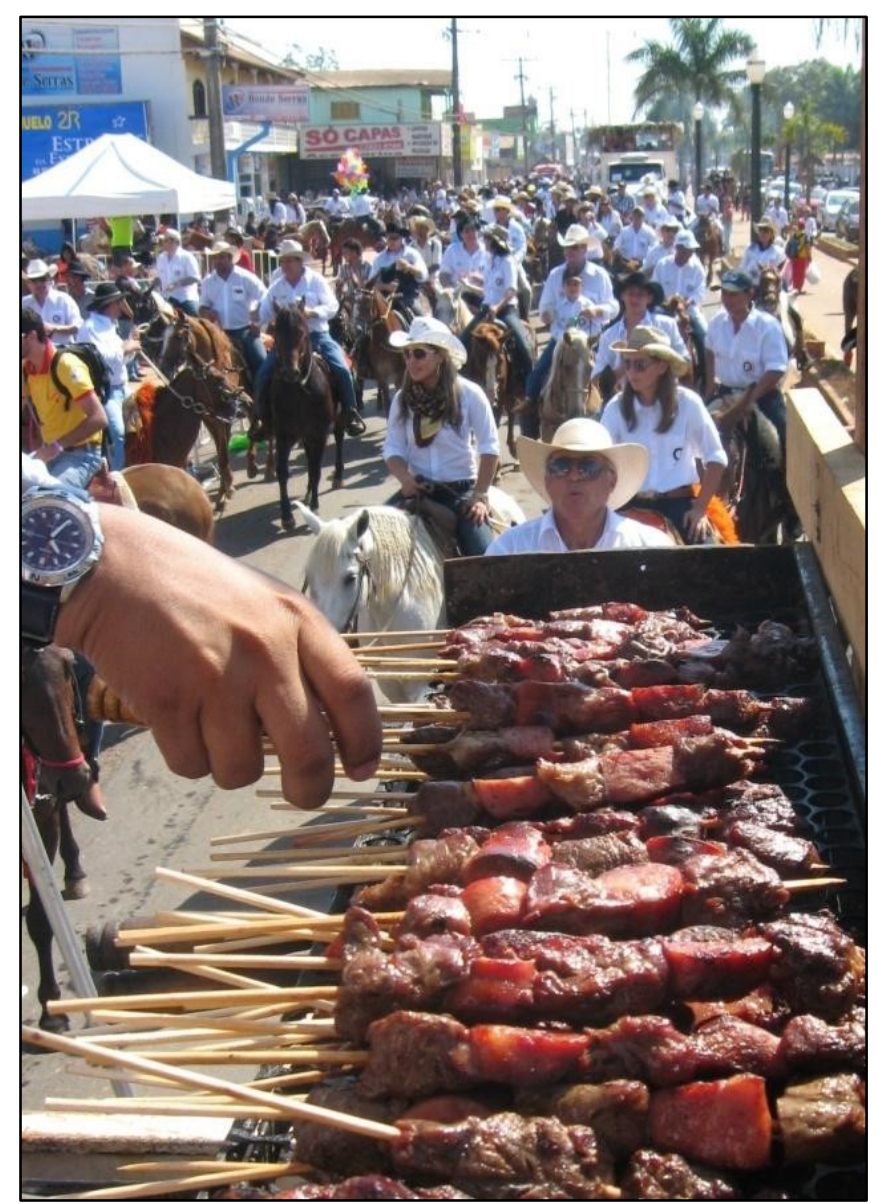

Figura 2 - Vista de um Trailer na Cavalgada de 2010.

Enquanto alguns Acreanos proíbem a matança do seu gado tratando-os como membros da família, um número crescente de indivíduos usa seu couro e consomem sua carne, ou simbolicamente define sua dominância sobre a natureza vencendo um rodeio, se conectando a tradições populares praticadas em todo o hemisfério. Existem, portanto, dois tipos de cultura de gado no Acre: o primeiro que provém de técnicas variadas na utilização para sobrevivência, e o outro, do modelo do caubói dominante fazendeiro orientado para o mercado. Esses modos de expressão cultural que são geralmente encontrados no pastoralismo do tipo "complexo do gado" da África do Leste e nas fazendas norte americanas, podem conviver na mesma casa Acreana. 
O objetivo desse capítulo é entender como maneiras distintas de usar o mesmo recurso dão origem a formas distintas de expressão simbólica no Acre, além de introduzir conceitos para compreender essa dinâmica em outros contextos. Eu faço a comparação dos meus dados etnográficos dos grupos rurais Acreanos (seringueiros, colonos agricultores e grandes fazendeiros) com a literatura sobre o complexo do gado no Leste da África e na América do Norte. Eu mostro como o modo de vida $(\mathrm{MoL})$ (pecuária ou pastoralismo) e o modo de produção $(\mathrm{MoP})$ (subsistência ou capitalista) estruturam, mas não determinam, maneiras de se expressar simbolicamente. Podemos entender algumas características dessas culturas de gado através desses contextos se nos focarmos ao nível das relações sociais e interações humano-animal.

Esse foco local, no entanto, ainda não é capaz de explicar inteiramente a emergência das práticas culturais caubói no Acre, então passo a analisar os caminhos que diretamente ou indiretamente permitiram que chegassem ao Acre. Em grande parte da literatura sobre expan são das fronteiras, o gado é um símbolo central de desenvolvimento destrutivo, deslocamentos e penetração capitalista. Ainda assim, alguns grupos adotaram a criação de gado como fonte de segurança econômica e reelaboraram formas culturais, ao mesmo tempo que participavam da cultura caubói associada ao comércio, produção e consumo capitalista. Ao analisar a articulação entre essas duas formas de criação de gado e expressão cultural, eu poderei definir melhor o que está ocorrendo no Acre em relação a um processo maior de produção e consumo capitalista, tanto de bens alimentícios agrícolas como de maneiras de se exprimir culturalmente.

Análises políticas, econômicas e orientadas para programas governamentais geralmente preocupadas com a diminuição do desmatamento, dominam o estudo do gado na Amazônia. No Acre, e em toda a Amazônia o gado é ao mesmo tempo desprezado pela sua influência na produção de conflitos sociais e na destruição do meio ambiente e desejado pelo seu papel singular em prover segurança econômica. Essas características econômicas positivas do gado são promovidas por uma visão idílica de uma vida rural centrada no gado - celebrada em festas, música e moda - que se apossou da região e está crescendo na mesma medida que cresce o gado nos campos dos pequenos proprietários de terra. E de muita importância de se prestar atenção à fatores sociais e culturais quase sempre menosprezados que explicam a importância que a criação de gado assumiu. Mais amplamente, uma visão holística do gado nos ajuda a entender melhor a expansão da criação de gado na Amazônia Brasileira, como principal motor do desmatamento e dos desafios enfrentados para um mundo mais sustentável. 


\section{AS BASES DOS COMPLEXOS E CULTURAS DE GADO}

Nas Américas, a cultura do uso do gado pode ser encontrada das planícies Canadenses até a Patagônia (SLATTA, 1990), mas criadores de gado no Novo Mundo ainda receberam pouca atenção em comparação com os grupos do Velho Mundo (RIVIÈRE, 1972; STRICKON, 1965). Essa ausência é particularmente notável para a Amazônia, ainda que pesquisadores tenham notado a tradição e "distinção vivida pelos ricos proprietários de terra e seus radiantes rebanhos brancos" (HECHT; COCKBURN, 1989: 152; ver também HECHT, 2012: 11; WALKER et al., 2000, p. 686 - 687; SMITH, 2002, p.41-74).

As força das construções culturais baseadas no gado nascem das excepcionais habilidades desses animais em armazenar valor, se adaptar os novos ambientes e transformar vegetação incomestível em alimento humano, produtos e serviços (DOVE; CARPENTER, 2007; RIFKIN, 1993; RIMAS; FRASIER, 2008). Ainda que, sobre animais sem valor funcional ou material, possam surgir teorizações culturais positivas (para a Amazônia ver DESCOLA 1994; VIVEIROS DE CASTRO, 1998; para uma visão geral ver MULLIN, 1999), meu foco aqui é nas explicações materialistas, como as análises através das culturas de Ingold (1980) das economias pastoris dos fazendeiros, pastores e caçadores. Tal vez, o argumento mais famoso seja o de Harris (1966) sobre os Indianos para quem relegar a vaca a uma esfera sagrada passa por uma combinação de fatores, incluindo o uso do gado para arar, além de limitações demográficas e ambientais. A pergunta é menos se as construções culturais em torno do gado emergem porque eles "são bons para comer" ou “bons para pensar” (LEVI-STRAUSS. 1969, p.89; HARRIS, 1985). Ao invés disso, eu argumento que para entender as raízes desses constructos culturais é necessário analisar que os animais "são bons para" produzir - seja leite, carne, preço da noiva, transporte, tração, ou alguma combinação destes.

Os pastores Leste-Africanos e fazendeiros Americanos possuem modos de vida distintos baseados no gado, cada uma das culturas dando origem a uma série de fatores únicos compondo um “complexo do gado" (HERSKOVITS, 1926; STRICKON, 1965). O gado Africano do Leste de Herskovits foi definido por uma complexidade de características, baseadas tanto na cultura material, como no campo social e simbólico - incluindo os mitos, rituais, regras de comportamento e tabus (1926, p.241), que são o resultado de uma maneira específica e duradoura de criação de gado.

O modo de vida pastoral nômade envolve pastorear os animais por uma extensa área sempre atento as respostas do ambiente indicadas pela sazonalidade, e dependência diária no produto desses animais, em geral, para subsistência, mas também para trocas matrimoniais e cada vez mais, economia de mercado (DYSON-HUDSON; DYSON-HUDSON, 1980). Dentro do "Complexo Pecuário Euro-Americano" (STRICKON, 1965) os criadores de gado foram 
influenciados por práticas e tecnologias Ibéricas de tratar o gado, e por isso culturas do gado estruturalmente similares se desenvolveram por toda a América (SLATTA, 1990). As práticas pecuárias no Acre são semelhantes a outras pelo continente, incluindo uma orientação para o mercado e o uso extensivo das terras, geralmente propriedade privada com contratação de trabalhadores (STRICKON, 1965).

A diversidade das práticas de criação de gado no Acre explica a economia variada existente nessa pequena área. Podemos encontrar desde grandes fazendeiros e um rol de estratégias de modos de vida com o gado praticado pelos pequenos proprietários de terra. Como já vimos, muitos seringueiros e colonos veem o gado como uma parte das suas estratégias de vida que inclui além disso, o extrativismo florestal, agricultura de corte e queima e trabalhado assalariado. Essas práticas podem mudar em decorrência de oportunidades e limitações, bem como o alcance que a produção terá para subsistência ou para o comércio. Em geral, o gado para subsistência proporciona leite e transporte de bens e pessoas aos pequenos proprietários. O gado e os bezerros mais velhos são geralmente vendidos para os intermediários que trabalham no campo, que por conseguinte, acumulam rebanhos de gados maduros prontos para o abate ou vendem esses bezerros direta ou indiretamente (através dos leilões) aos fazendeiros. Eu uso a expressão "criação de gado" como um termo guarda-chuva para todos aqueles sistemas misto, bem como os modos de vida mais puros pecuária e pastoreio.

No Acre, é possível encontrar aspectos do complexo do gado descrito acima em diversos contextos. Além disso, o sistema misto do pequeno proprietário, encontrado aqui, onde o gado amado (incorporado às rotinas domésticas, recebe um nome, é tido como um animal de estimação), e as commodities sem nome pastam lado a lado no mesmo rancho, não se encaixa totalmente em nenhum complexo. Me parece então, que fatores que vão além da pecuária e do pastoreio dão origem a certas características culturais do complexo. Para isolá-los e analisá-los é necessário que separemos a mistura imprecisa entre fatores econômicos, ecológicos e sociais que compõe esse modo de vida. Eu me volto, assim, para o modo de produção: o sistema econômico mais abrangente que governa a produção, o consumo e o comércio. O MoP fornece uma variação de relações ecológicas e sociais as quais podem ser reduzidas as relações de produção (RoP) (humano/humano ou relações sociais) e os fatores de produção (FoP) (humanos/recursos ou relações ecológicas) (MARX [1867], 1977); WOLF, 1982; ROSEBERRY, 1989). Tal comparação sistemática torna possível identificar as raízes dos diferentes modos de expressão simbólica no Acre. Dado que as descrições mais bem sucedidas da cultura do gado venham do Leste Africano, eu a uso como modelo para compreender relações semelhante no Acre. Eu limitei meus estudos a leituras selecionadas fundamentais para a primeira metade do século XX (“período-colonial”) e a alguns textos contemporâneos importantes que tratam das mudanças econômicas e sua implicação nas 
práticas culturais a ela associadas na segunda metade (“período pós-colonial”). As inúmeras variáveis políticas, institucionais e ecológicas têm também um importante papel na estruturação das economias do gado na África (por exemplo ENSMINGER, 1992; GALVIN, 2009; McCABE, 2004) estão, infelizmente, além do escopo dessa pesquisa.

\section{CULTURA DO GADO NO LESTE dA ÁFriCA, NAS AMÉRICAS E NO ACRE}

Na Leste da África na época colonial, o pastoreio era caracterizado pela mobilidade do gado e da família que possuía e dependia dele, de acordo com mudanças sazonais e disponibilidade de recursos (HERSKOVITS, 1926). A unidade familiar cuidava do gado e consumia os produtos derivados dele diariamente. Como resultado dessa relação de mútua dependência e coabitação, intensos laços emocionais se desenvolviam entre o pastor e seu gado. Os Nuer, por exemplo, dormem entre o gado e logo pela manhã, se enxaguavam na urina da vaca e nas cinzas do fogo consumido (EVANS-PRITCHARD, 1940). Dado essa interação intima entre humanos e gado, a demonstração natural de afeição dos pastores aos seus animais criou um vínculo simbólico através de práticas de nomeação, e eram comidos apenas em ocasiões sociais permitidas (HERSKOVITS, 1926; EVANS-PRITCHARD, 1940; SCHNEIDER, 1957). Ao contrário, em uma transação pecuária Acreana típica, o valor econômico do gado se dá através de sua venda no mercado, onde eles são esquartejados e divididos em pele, sebo, carne e outros produtos. Os proprietários (fazendeiros) gerenciam o trabalho dos peões proletários, cujo objetivo é apenas assegurar a continua produção e retirada da carne em troca de salários. Esses peões não estão devotados ao gado econômica ou emocionalmente, nem tampouco eles o usam para seu sustento direto ou para seu lucro pessoal.

Existe uma diferença, portanto, entre o gado que é valorizado pelo que ele produz e o gado que adquire valor apenas quando ele é trocado, esquartejado e convertido em produto e moeda. Essas diferenças no valor de uso e no valor de troca são características fundamentais do modo de produção doméstico ou de subsistência e do capitalista (MARX [1867], 1977; SAHLINS, 1972). Enquanto esses conceitos são fundamentais para delinear as diferenças, essas distinções não são simples de serem feitas. Por exemplo, pastores prescindem da utilidade do seu gado trocando-os em redes de obrigação mútua (DESHLER, 1965, p.154), geralmente como uma fonte de preço da noiva (COLSON, 1955). Mesmo que os pequenos proprietários acreanos vendam seu gado, já houve ocasiões em que o churrasco foi usado para fazer um mutirão - basicamente movimentando sua própria rede de reciprocidade.

$\mathrm{Na}$ África pós-colonial, as trocas econômicas e políticas deram origem ao aumento do comércio capitalista que se refletiram, por sua vez, na relação entre as pessoas e entre as pessoas e o 
gado (DYSON-HUDSON; DYSON-HUDSON, 1980; MOORE, 1993). Características associadas com a pecuária capitalista foram aparecendo por toda a África pós-colonial subsaariana (não apenas África do Leste), não mais incluindo o ritual de abate do gado, identificando o gado a uma commodities onde pastores que são trabalhadores assalariados tornaram-se alienados dos meios de produção (COMAROFF; COMAROFF, 1990; FERGUSON, 1985; HUTCHINSON, 1996; MORITZ et al., 2011). Sabendo das raízes históricas e ecológicas da atividade pastoral, essas mudanças têm acontecido apenas irregularmente e são vistas criticamente. As estruturas culturais originais não foram completamente subsumidas, mas as mudanças que vem ocorrendo indicam uma intensificação do capitalismo de relações estruturais MoP entre humanos e gado, de tal forma que expressões simbólicas emergem - independentemente do contexto.

Por exemplo, entre os Tshidi, a "economia total” do gado foi substituída por uma economia monetária. Eles se referiam ao dinheiro como um "boi sem as pernas" uma metáfora a sua inabilidade em cumprir obrigações sociais (COMAROFF; COMAROFF, 1990). De modo semelhante, os famosos Nuer falam de um dinheiro "sem sangue". A perda de controle sobre o gado foi relacionada a uma reestruturação da organização política e social e da prática ritual (HUTCHINSON, 1996). Essas experiências exemplares da África mostram como a transição das práticas de subsistência, socialmente mediadas para o comércio baseado na moeda pode ser conflitivo exigindo a renegociação de valores culturais e das relações sociais; da carne e sangue e tecido conjuntivo do gado para o objeto frio e comodificado. Essas expressões Africanas, ilustram a longevidade das interações e profundidade das construções culturais ao redor do gado, e mesmo nos lembram os termos Acreanos para gado: poupança e dinheiro vivo.

Podemos ver que, nos dois cenários, existem algumas diferenças em como o gado é percebido e tratado. Na África, o MoP não suprime completamente outras formas de expressão cultural e nas Américas, pequenos proprietários ainda nomeiam parte do seu gado e vendem o resto. Ainda que estruturada pelo $\mathrm{MoL}$ e MoP, a característica que define as expressões culturais parece ser a forma como os humanos interagem com o gado.

Mesmo entre os Nuer, "ao fim, toda carne ia para a panela" (EVANS PRITCHARD, 1940, p.38). Nesse sentido não é o fim (comércio e consumo) que importa, mas os meios, ou o processo de produção - os modos com que os humanos interagem com o gado para garantir os produtos e serviços que eles dependem e retiram. Animais que são importantes como valor de uso terão que ser domesticados para que produtos úteis possam ser extraídos. Quando inseridas nas estruturas econômicas e sociais que ditam as relações de produção, o relacionamento ecológico entre humanos e gado pode iluminar como as diferentes formas de cultura do gado emergem, seja acrescentando valor ao gado por ele mesmo ou vendo-o como dinheiro impessoal. Do nascimento, até a panela ou o churrasco, é o que vem no meio da forma de interação entre humanos e gado que gera modos 
únicos de expressão simbólica. Como prova adicional dessa relação econômica, não o MoP, nem o MoL, podemos olhar para as relações entre os cavalos os caubóis proletários no seio da empresa pecuarista capitalista.

\section{FATORES DE PRODUÇÃO: O CHICOTE O CARINHO PELOS CAVALOS?}

Na produção dos sistemas pecuários de larga escala, os caubóis apenas separam o gado que causam tumulto ou que precisam de um pouco mais de atenção. Para eles é perfeitamente normal usar a força sobre esse gado sem nome, que nessa visão, não são mais que apenas commodities móveis e as vezes, obstinadas. Em um outro extremo, na maioria das vezes os caubóis nomeiam seus cavalos, nunca os comem, e quase sempre os enchem de abraços, fazem carinho e se esfregam neles. Por quê?

Sem um cavalo, é praticamente impossível para um caubói controlar grande quantidade de gado, ou da forma como as operações pecuárias exigem, com suas vastas terras e rebanhos, limitado número de trabalhadores, e com a necessidade de deslocar o gado de um lugar a outro. Os cavalos servem como intermediários que evitam que o caubói entre em contato direto com o gado transformando o que seria outrora um delicado embora inteligente bípede em um alto, forte e veloz centauro. O cavalo, literalmente, coloca o caubói acima da vaca, elevando-o simbolicamente sobre o mundo natural.

Para o caubói, os cavalos são um fator de produção, mais especificamente, eles são um instrumento de produção, uma ferramenta fundamental para a produção da carne de boi. De modo semelhante, os pastores e seu gado estão atados a uma relação de interdependência: o gado vivo produz o que os humanos dependem para viver. Como resultado desse mutualismo, e das muitas horas de treino e interação que são necessárias para domesticar um cavalo selvagem ou para treinar o gado para puxar o arado ou dar leite, naturalmente, criam-se laços entre humanos e animais. $\mathrm{Ou}$, no caso do touro de raça Acreano ou do sinuelo (treinado para liderar o rebanho de um lugar a outro) não existe nenhum tipo de laço ou interação, apesar de os serviços realizados por esse tipo de gado contribuir enormemente para a produção de modo mais valioso do que o seria apenas sua carne.

A parte das conexões das relações econômica, social e ecológicas, outros fatores como a disponibilidade dos cavalos, exercem influência na criação de culturas de gados singulares. Mais do que isso, elas mostram que quando o valor de um animal como ferramenta ou recurso na subsistência diária excede seu valor como mera carcaça, associações simbólicas irão se formar entre humanos e esses animais, sejam eles cavalos ou gado. Isso é verdade na medida que alguma forma de interação duradoura é necessária para extrair produtos vivos ou usar os animais. 


\section{O CHURRASCO DE BAIANA: A ARTICULAÇÃO dOS MOdOS DE PRODUÇÃo E CULTURAS DE GADO}

A vida econômica pela fronteira amazônica da década de 1970 e 1980 seguia um padrão familiar. Intensificação das relações de produção capitalista, alienação dos meios de produção e remoção de formações sociais preexistentes (FOWERAKER, 1981; SCHMINK; WOOD, 1992). As relações capitalistas têm aumentando sua intensidade ao longo do tempo e ao redor do mundo todo, mas os resultados do capitalismo são sempre imperfeitos e por isso, pode-se encontrar variações nas práticas econômicas locais (CLEARY, 1993; FERGUSON, 2006; WOLF, 1982). MoP diferentes podem coexistir em um mesmo espaço interagindo de diversas maneiras possíveis (MEILLASSOUX, 1980; WOLPE, 1980). Pesquisas sobre a articulação dessas MoP geralmente expõe transformações econômicas e sociais, tais como os conflitos interculturais que resultam de tais encontros (HOPKINS, 1978; ROBBEN, 1989). Menos estudadas, no entanto, são as maneiras em que formas de expressão simbólica ligadas a diferentes modos de produção são negociadas pelas pessoas nesses espaços de encontro. Por toda a Amazônia, grupos tem adotado a criação de gado e adaptando-o ao seu sistema de produção misto (LOKER, 1993; RUDEL et al., 2002). Aqui eu dou um exemplo e faço uma análise da maneira com que os pequenos proprietários de terra operam e negociam as características culturais entre o MoP doméstico e o capitalista.

A colona Baiana vivia em um ramal, algumas dúzias de quilômetros rodovia acima de Jatobá. Seu pai era agricultor no árido Nordeste, onde ela cresceu rodeada de gado, antes de casar e se mudar na sua adolescência. Ela e seu marido, que frequentemente trabalhava como caubói seguiram a frente pioneira até os estados de Goiás e Mato Grosso, até se assentarem perto de Rio Branco, no começo dos anos 1980. Em 1986 ela comprou um rancho de 80 hectares de terra no assentamento dirigido do Quixadá. Ela viveu lá com seus filhos e netos até vende-la em 2009 para um fazendeiro.

Logo depois que ela e seu marido chegaram no Acre ele caiu de seu carro de boi e foi esmagado pelas rodas. Apesar dessa memória dolorida, Bahiana não guarda rancores dos seus dois touros que ela geralmente amarrava a uma árvore de manga perto da frente da sua casa (figura 3). Seus filhos usavam os animais para carregar lenha ou outro tipo de carga. Nos finais de tarde, depois de um dia de trabalho, Bahiana os dá um punhado de sal antes de soltá-los para se juntarem ao resto do rebanho que estava cercado no morro acima de onde morava. Baiana acabou desenvolvendo uma relação íntima com seus bois, mas sem nome, ela continuou chamando-os de "meus bois." Seus filhos trabalhavam com as oitenta cabeças de gado de corte separando-os por cor e marcas, sexo, status reprodutivo e idade. 


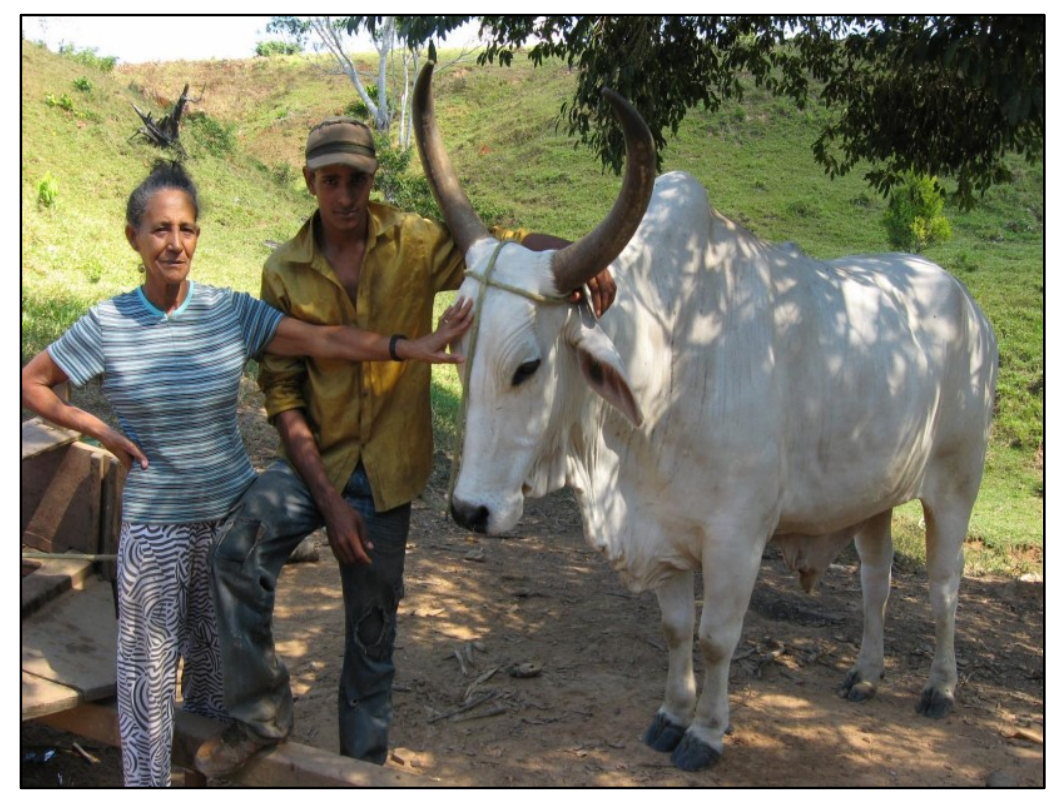

Figura 3 - Baiana, seu filho e seu boi.

Schneider nos assegura que a essência do complexo Africano está em um "tipo de identificação com o gado que leva a sua associação ritual" (SCHNEIDER, 1957: 278). Enquanto o pastoreio de subsistência fortalecia a interdependência entre as pessoas, e na seara ritual, entre as pessoas e seu gado (EVANS-PRITCHARD, 1940), as relações capitalistas e fatores de produção reforçados pela pecuária reestabelecem relações comodificadas baseadas na transformação do trabalho, propriedade privada e carne animal em moeda. A diferença conceitual entre humanos e gado é reencenada em rituais populares como os rodeios, onde os humanos simbolicamente asseguram sua superioridade sobre os animais (LAWRENCE, 1990).

A análise de um ritual que está presente em ambas sociedades - o consumo ritual da carne - exemplifica como relações econômicas diferentes com os animais passam para o âmbito ritual. No período colonial Leste Africano, a matança do gado era estritamente supervisionada e limitada a ocasiões cerimoniais, ainda que isso esteja mudando no período pós-colonial (HUTCHINSON, 1996). No Acre o churrasco é uma exuberante instituição social centrada no consumo ritualístico da carne e geralmente acontece para celebrar eventos importantes, como as férias ou partidas de futebol decisivas. Ainda que o ritual esteja presente em diferentes contextos, e o gado, então é usado das mais variadas maneiras, o churrasco no Acre só é possível devido a produção comercial de carne, sua compra e seu consumo o que me faz classificá-lo como uma expressão cultural da economia pecuária capitalista. A maioria dos consumidores não tem nenhuma relação com a criação, abate, venda, subdivisão e armazenamento da carne desse animal. No entanto, no contexto rural, o animal todo pode ser doado ou comprado para ocasiões festivas, ou para um mutirão como limpar um terreno.

Durante o mês que precedeu sua mudança para a cidade eu estava vivendo com Baiana e seus filhos e estava em lugar privilegiado para observar como ela terminou sua relação com seu 
gado de corte e com seus touros. Ela vendeu todo seu gado sem pensar duas vezes. Ela não podia conceber, no entanto, seus dois bois condenados ao matadouro. Ela podia os ter vendido por um bom preço, mas ao invés disso, ela fez seu filho prometer que iria deixar o touro pastar naquelas pastagens pelo resto de suas vidas.

Baiana ofereceu um churrasco de confraternização algumas semanas antes de se mudar. Além de estar protegido pelas ordens de Bahiana, o touro era grande e velho demais para a ocasião além de não ser tão apetitoso quanto o bezerro que ela comprou do vizinho. Apesar de, basicamente, tratar-se dos mesmos animais, o touro era definido por anos de uso e interação, enquanto o bezerro era uma commodity. Enquanto seu touro não tinha preço, seu inominado gado podia ser comprado, abatido, pendurado em uma árvore e esquartejado. Seus filhos assaram a carne fatiada em uma grade de arame farpado que cobria um buraco de um metro de profundidade, forrada de carvões brilhantes.

O churrasco de Baiana mostra de que maneira os modos da economia do gado e expressão simbólica se sobrepõe, convivem, mas se mantem distintos. Elaborações culturais que surgem de maneiras distintas de usar o gado coexistem no mesmo espaço, mas aquele gado com os quais as conexões simbólicas são estabelecidas não circulam em rituais como os do churrasco - uma expressão das relações comodificadas de troca. Esse exemplo também chama a atenção para uma questão interessante: modos de expressão simbólica nascidos com o gado de subsistência, mesmo que semelhantes ao complexo do gado Leste Africano não atingiram esse nível de significação no Acre. Essas características de subsistência da cultura do gado estão subordinadas a cultura caubói dominante, baseada na pecuária, que constitui um complexo na medida em que as relações com o gado foram institucionalizadas na esfera do ritual. Agora temos um base nas relações materiais locais para entender os raízes das culturas de gado, mas isso não explica a profundidade dessa cultura caubói. Para entender isso, temos que olhar as rotas de migração de difusão.

\section{A DISPERSÃO da CULTURA CAUBÓI ATÉ O ACRE}

Tatu, o filho de Bahiana, era um colono típico, que nas suas terras criava gado de corte e fazia agricultura. Quando Tatu foi a cidade de Brasiléia, no entanto, ele se transformou em um caubói. Eu ainda posso imaginá-lo batendo suas botas na calçada, chapéu caubói preto, jeans azul e camisa xadrez, a fivela de seu cinto reluzindo o brilho do sol. Na cidade, Tatu visitava frequentemente Branco, seu irmão mais velho, que dirigia um caminhão de entregas, porém "vivia para" os finais de semana, ocasião em que montava touros no circuito de rodeio local. A última vez que eu vi Branco ele estava competindo no rodeio O Raio da Lua, descrito na introdução dessa pesquisa, apenas alguns quilômetros de onde tinha crescido com Bahiana. Em eventos como essa, 
havia outros com pouca, senão nenhuma, conexão ao meio ou a uma existência rural, pessoas como Sorocaba, que eu mencionei ao começo deste capítulo na cavalgada.

Sorocaba, Branco, e Tatu tinham graus variados de conexão com o estilo de vida econômico e ecológico da pecuária representada pela cultura caubói. Eles se pareciam na medida que todos eles perseguiam um estilo de vida baseado no gado e simbolicamente através de traços da cultura popular como os rodeios, churrascos e moda. Para que possamos entender como essa cultura caubói se instalou e se difundiu por toda a sociedade Acreana, devemos olhar para além das práticas de pecuária locais para conexões que atravessam o espaço e o tempo. Especificamente para o processo de difusão direta e indiretamente, circulação de significados e fatores locais que contribuíram para essas apropriações.

O gado Ibérico chegou nas Américas em 1521 no que é hoje o México e se espalhou, a partir do século seguinte, para outras regiões da América do Norte e Sul (BISHKO, 1952; DARY, 1981; JORDAN, 1993). As técnicas e outras características culturais da criação de gado nas Américas se desenvolveram a partir de suas raízes Ibéricas, mas tornaram-se particulares, à medida que criadores de gado se adaptavam aos novos contextos econômicos, ecológicos e políticos (BUTZER 1988; SLATTA, 1990). Essas culturas de gado Americanas partilhavam de semelhanças estruturais que vieram de sua dedicação comum a pecuária do gado: um padrão ecológicoeconômico caracterizado pela orientação para o mercado, produção extensiva, e o uso de caubóis proletários para trabalhar com o gado (STRICKON, 1965).

Desde os huasos e os gaúchos do cone Sul aos charros e vaqueros do México aos cowboys da América do Norte, ricas culturas se desenvolveram através da prática de criar gado (SLATTA, 1990). No Brasil, surgiram duas tradições principais de caubói regional: os vaqueiros do árido nordeste, e os gaúchos das campanhas do sul, nos pampas. Cada uma delas realizou adaptações materiais únicas e desenvolveu visões de mundo próprias, como Euclides da Cunha (1994, p.91-92) notou para Os Sertões: “O gaúcho do Sul, ao encontrá-lo (o vaqueiro) nesse instante, sobreolhá-loia comiserado. O vaqueiro do Norte é a sua antítese (...) O primeiro, filho dos plainos sem fins, afeito às correrias fáceis nos pampas, percebe seu ambiente como amigável e fascinante (...) [Ele] não se entristece com as cenas periódicas da devastação e da miséria (...) As roupas que ele veste são despojadas se comparadas aos rústicos pedaços de roupa dos vaqueiros".

Culturas de gado Brasileiras secundárias se desenvolveram a medida que os gaúchos e vaqueiros migravam adaptando suas práticas aos novos contextos. Por exemplo, os migrantes do nordeste levaram a criação de gado para o lavrado de Roraima, no nordeste Amazônico. Na transição do deserto para o lavrado os vaqueiros "se desfizeram das roupas de couro, que, tão fundamentais entre os espinhos arbustivos da caatinga, era quase desnecessário nos campos abertos" (RIVIERE, 1972, p.35). 
Em outros casos de migração, as tradições culturais se adaptavam a novos contextos ecológicos. Por exemplo, a criação de gado no pantanal Brasileiro tem sua origem na migração dos gaúchos e sua adaptação ao regime sazonal das águas (MAZZA et al., 1994). A tradição do gaúcho em beber chá de erva mate (chimarrão) foi preservada pelos pantaneiros, influenciada ainda pelo vizinho Paraguai. Os Acreanos bebem chá mate, na maioria das vezes como tereré, dependendo se forem noites frias ou mesmo durante as friagens, muitos preferem o chimarrão. Eu bebi tereré e chimarrão no Acre e também com os pantaneiros no pantanal e o que eu posso dizer é que mesmo que a temperatura da bebida varie seus códigos de etiqueta e função social compartilhada, não.

Esses relatos de difusão cultural, centrados na cultura material, oferecem uma maneira de contextualizar a história das culturas de gado no Brasil, sinalizando para a diversidade de práticas que emergiram em resposta as limitações ambientais e estabelecendo conexões entre as regiões, mas eles ainda não contam a história toda. As tradições regionais Brasileiras exerceram apenas influência parcial no Acre e a adaptação exerceu apenas papel secundário na criação da moda caubói. É necessário, então, olharmos para os processos diretos e indiretos de difusão que levaram o gado e os criadores de gado para a Amazônia Ocidental nos anos de 1970, bem como as conexões para além das fronteiras brasileiras.

A maioria dos grandes fazendeiros Acreanos vieram da região centro-sul do Brasil, especialmente os estados de São Paulo e Minas Gerais. Esses sulistas (do Sul) ou paulistas (nativos do estado de São Paulo) como são referidos no Acre, começando nos anos 70, estabeleceram a infraestrutura econômica e técnica necessária para a difusão da indústria do gado. Cicero, com mais de cinquenta mil cabeças de gado, é um dos maiores fazendeiros do Acre. Ele foi criado em uma cidade a oeste de São Paulo que é famosa por sua tradição de criação de gado e cavalos. A King Ranch, uma fazenda famosa do Texas funcionou por muitos anos ali (LEA, 1957) e, ainda jovem, Cicero aperfeiçoou seus conhecimentos sobre a criação de gado ao trabalhar com NorteAmericanos. Em seu escritório estão expostos inúmeros troféus ganhos por seus filhos em rodeios e competições de laço organizado pelos Norte-Americanos. Cicero veio ao Acre fazendo planos para uma fazenda de gado, além de amar rodeios. Ele transmitiu esse gosto também para os seus netos que passam as tardes participando de rodeios nos arredores de Rio Branco. Treinando os nativos Acreanos para serem peões da sua fazenda, ele difundiu práticas pecuárias, cultura material e o interesse por rodeios e outras tradições culturais.

Os migrantes trouxeram a necessária tecnologia e infraestrutura para o estabelecimento da indústria do gado e plantaram a semente para a cultura caubói, mas os caminhos indiretos de difusão mudaram a escala da coisa. A cultura caubói começou na cidade de Barretos ao norte do estado de São Paulo. Desde os anos 1900 esse era o final da linha das comitivas que carregavam viveres ao mercado. Os caubóis então, passavam a se entreter competindo uns com os outros em 
provas de habilidade baseadas em práticas pecuárias. Esses eventos informais foram institucionalizados em 1955 na Festa do Peão de Barretos (DENT, 2009: 7; GONÇALVES; IACOMINI, 1997). Os rodeios Norte-Americanos têm origem semelhante (STOELTJE, 1989), indicando caminhos nos quais a economia da criação de gado orientada para o mercado, construídas sobre tradições comuns Ibéricas, deu origem a formas de expressão ritual semelhantes nas regiões da América (STRICKON, 1965). No final dos anos 1980 a crescente popularidade da música sertaneja inspirou empresários locais que decidiram transformar o festival em um tipo de "torneio Texano" com o objetivo de atrair patrões das classes média-alta que nunca se interessariam em participar de um festival caipira, mas não pensariam duas vezes em ir a um evento "country" (GONÇALVES; IACOMINI, 1997).

A fusão das tradições Brasileiras e rurais Norte-Americanas junto com influências ocidentais produziu uma nova imagem do campo onde consumidores e os campesinos poderiam celebrar a tradição rural no que antes era desdenhado como atrasado e do interior. Essa vida country/cultura caubói se espalhou pelo Acre, na televisão, música, circuito de rodeio e imigração, mas como e que foi apropriado num lugar como Acre?

\section{DESENVOLVIMENTO E SAUDADES NAS CIDADES}

A cidade é feita de uma diversidade de pessoas, de Sorocaba à Bahiana. Eles tiveram experiências diferentes, para dizer o mínimo, mas estão unidos residindo na cidade ao mesmo momento da história. À medida que as cidades da Amazônia crescem, ninguém mais quer verdadeiramente uma vida na floresta, mas também não estão totalmente satisfeitos com a nova vida urbana. Será que olhando nas cidades podemos entender algo do crescimento da "cultura de gado"? A história que trouxe o gado e a migração para a Amazônia na década de 1970, e que gerou uma resistência a pecuária e suas práticas culturais, também criou as pré-condições demográficas, econômicas, sociais e políticas para que a "cultura de gado" ressoasse no presente.

Muitos Acreanos dizem que a modernidade e o progresso chegaram com a BR-364 que conectou o estado com o resto do país na década de 1970. A partir desse momento, o Acre passou a se "desenvolver" - caminhos lamacentos viraram ruas pavimentadas, água e eletricidade ficaram mais acessíveis e artigos escassos estavam mais disponíveis. Com a chegada dos migrantes conflitos de terra tornaram-se mais frequentes com a consequente expulsão dos seringueiros nativos a maioria dos quais foi tentar a vida na cidade (BAKX, 1988). As cidades no Acre estão cheias de pessoas que deixaram suas propriedades rurais para tentar uma vida urbana melhor (SCHMINK e Cordeiro, 2008) tendência da Amazônia e no Brasil do final do século vinte (BROWDER e GODFREY, 1997). O processo desenvolvimentista iniciado pela abertura da colonização da 
Amazônia criou linhas elétricas e estradas que iriam introduzir novas formas de uso da terra e as mensagens culturais da vida rural associadas a ela, do centro à periferia.

Bahiana que passou por diversos lugares dessa colonização buscando terra foi fatalmente atraída para a cidade pela promessa de melhor saúde, educação e segurança. Ela e outros na mesma situação romantizavam a vida que deixaram para trás, relembrando sentimentos de autonomia e tranquilidade. Urbanóides como Sorocaba, por outro lado, também expressavam uma nostalgia do campo incrementada inclusive por não estarem familiarizado das suas agruras - imaginando cenas de pureza e tradição contrastada com "o crime, o barulho e a pressão" da cidade. Alguns habitantes de cidades mais tradicionais do Centro-Sul Brasileiro criticam o processo de modernização que os separou da terra deixando-os a procura de um passado rural idealizado (DENT, 2009; OLIVEN, 2000).

Muitos Acreanos conseguem expressar seus sentimentos através da palavra saudade, que é uma mistura de desejo, perda, e nostalgia - neste caso específico a respeito da vida rural e do campo. Para a maioria, a saudade pode ser liberada através da cultura caubói, expressão que propicia uma conexão simbólica com um passado rural idealizado ou presente menos complicado uma espécie de "era de ouro" mítica que na verdade, nunca existiu (WILLIAMS, 1975).

Dado a preferência histórica urbana e internacional (Europeia) das expressões da cultura popular Brasileira, tendência essa sempre explorada pelas novelas mais populares dos finais de tarde (KOTTAK, 1990; PACE, 2009; PACE; HINOTE, 2013) as conexões internacionais da cultura caubói reforçam o apelo e legitimidade desse tipo de expressão rural por todo o Brasil, e particularmente no Acre. Esse senso de conexão nacional e internacional é importante de ser notado dado a marginalidade da posição do Acre frente ao restante do país. Ainda que os Acreanos sejam extremamente orgulhosos do seu estado, muitos concordam que ele fica "no fim do mundo".

Ainda que não corresponda exatamente com a experiência, a cultura caubói é a única forma de identidade rural que é avaliada positivamente e completamente institucionalizada por todo o Brasil. Liga pessoas que tenham alguma relação com tradições rurais, do Acre à São Paulo, e para além das fronteiras. Poucos, se não nenhum Brasileiro deseja ser associado com o caipira representado nas Festas Juninas banguela, com sardinhas e roupas remendadas. Em menor número ainda buscariam traçar ou celebrar conexões com os grupos Amazônicos considerados ainda mais selvagens e estranhos quando comparados caipira - caboclos, ribeirinhos, seringueiros e povos indígenas.

É importante ressaltar que a cidade e a floresta são dois extremos que representam não só diferentes espaços, mas também evoluções e estágios temporais diferentes na cabeça das pessoas. Considera-se que os habitantes da floresta foram corrompidos pelo seu contato com a natureza e portanto, tornaram-se menos humanos, enquanto que os moradores da cidade amoleceram e foram 
pervertidos pela sua alienação ao trabalho na cidade. A zona rural, visto como o country, e um meio termo entre a floresta e cidade, no entanto, é visto como um lugar para trabalhar duro, tornar-se auto suficiente, ar puro, brisa de final de tarde e refeições como a nossa vó costumava fazer. Ainda que nunca tenha existido no Acre, a pessoas sentem que existia antes num passado romantizado.

Muitos dos que permaneceram vivendo no campo dizem que as músicas sertanejas não descrevem bem como se vive ali. Ainda assim, a cultura caubói dá voz para uma forma ecológica específica onde humanos submetem a natureza ao seu controle criando paisagens antropogênicas. Essas mensagens ressoam com a ideologia desenvolvimentista que propõe políticas Amazônicas que encorajam os residentes a derrubar a floresta para os espaços produtivos. O Acre, que dá ênfase à preservação da floresta e modos de vida mais sintonizados com a natureza, frustra os planos de “desenvolver" e "fazer progredir", e muitos Acreanos rurais reclamam de ser injustiçados pelas leis ambientais que limitam as queimadas e o desmatamento. A cultura caubói é a queixa da oposição à preservação ambiental, e veem os esforços de preservação como uma afronta à auto suficiência dos produtores rurais, componente central da formação da sua identidade, particularmente dos migrantes que apostaram na Amazônia para construir seu futuro.

Enquanto muitos se mudaram para a cidade, a agricultura Brasileira cresceu colocando a nação no topo da lista da produção global e exportação de diversas commodities agrícolas, incluindo a carne. O crescimento a nível nacional da cultura caubói pode ser vista como uma parte e parcela das oscilações econômicas e demográficas do processo racional, industrializado, mecanizado e comodificado do capitalismo e do alargamento da classe média de origem rural. Ainda que sua popularidade esteja crescendo, seria precipitado dizer que esse estilo de vida é aceitado acriticamente, visto que as pessoas lamentam a perda tanto da produção econômica quanto cultural. As commodities agrícolas são produzidas em uma escala que não reflete as práticas produtivas centradas na família que um dia caracterizaram esses sujeitos culturais do campo.

Durante o pouco tempo que eu estive no Acre eu vi pessoas irem da admiração por todos os produtos sendo vendidos no supermercado até a reclamação da falta de gosto da galinha de granja e do milho. Para muitos o meio de valorizar essa vida rural já desaparecida parece ainda mais artificial e prosaica do que a comida. Os habilidosos novos cantores de sertaneja não se parecem em nada com a geração anterior de velhos contadores de histórias, que mesmo sem vozes treinadas, tinham "emoção" e sensibilidade rural. É através dessas expressões que podemos ver de que maneira a economia e a cultura de massa estão relacionadas no pensamento da maioria dos Acreanos que se distanciam da idílica vida rural que eles se esforçam por representar em direção a um pacote comodificado e de produção em massa, seja o milho sem gosto ou novos estilos musicais. 


\section{PENSANDO NO BOI EM AMAZÔNIA}

Eu me propus a descrever como ela chegou a esse lugar único da Amazônia Brasileira. “Olhar para a vaca”, nesse sentido, exigiu que analisássemos, no entanto, as distintas estratégias produtivas que deram origem a formas locais de expressão, mas também, prestar atenção na difusão da pecuária associada a cultura popular e seus significados, e a forma com que esses conteúdos econômicos e culturais se sobrepõe e interagem.

Ao comparar a literatura do Leste Africano com as minhas descobertas no Acre, pude mostrar que as economias do gado carregam certos significados simbólicos através dos diferentes contextos. Entre aqueles que criam gado para venda no mercado, uma característica associada, mas não exclusiva a pecuária, a relação entre humanos e gado tende a ser mais impessoal. Mesmo que os usos do gado para a subsistência dos Acreanos não sejam homogêneos e longevos, como na época colonial Leste Africana, a intimidade da interação e dependência pode produzir resultados similares sobre o gado através desses contextos. Os casos da África pós-colonial e dos caubóis Acreanos e seus cavalos indica que as formas de expressão simbólica podem estar estruturadas, mas não determinadas, mais amplamente, pelo contexto econômico e ecológico. Ao final, acho que tudo se reduz a nomeação de um animal como tendo valor de uso ou de troca e as relações que são constituídas entre as pessoas e seu gado destinadas a extração de determinados produtos.

O crescimento da economia do gado e da "cultura de gado" no Acre pode ser interpretado de diversos modos. Por um lado, uma subclasse rural se apropriou do símbolo principal do avanço do capitalismo e o utilizou para se apoiar em alguma forma de determinação econômica, em detrimento de forças econômicas regionais, nacionais e globais. A cultura caubói dominante que se preocupa menos com uma relação de produção imediata e mais com uma articulação remota ou parcial com esse modelo de produção mais difundido, representa, todavia, um modelo para a expressão de formas de produção mais intimistas. A produção do gado de subsistência, ao mesmo tempo que cria formas culturais autônomas de expressão, abre espaço para essas formas de cultura caubói mais difundidas criarem raízes.

Para concluir, eu gostaria de ressaltar mais um componente vital para entendermos a expansão da criação de gado no Acre. O gado propicia mais benefícios materiais do que outros animais, e a criação de gado, seja na sua forma de pastoreio, pecuária ou subsistência mista, geralmente resulta na criação de elaborações culturais positivas em torno desses animais. Assim, favorável as características que favorecem o gado dentro dessa matriz de fatores políticos, econômicos e sociais, somam-se os valores econômicos e culturais quase universais sobre o gado. As estruturas políticas e econômicas são fundamentais para entender o crescimento da criação do gado, mas a cultura, ela mesma, é um fator crítico nessa equação. 


\section{REFERÊNCIAS}

ARIMA, E.; BARRETO, P.; BRITO, M. Cattle Ranching in the Amazon: Trends and Implications for Environmental Conservation. Belém: IMAZON, 2006.

BAKX, K. From Proletarian to Peasant: Rural Transformation in the State of Acre, 1870-1986. The Journal of Development Studies, v. 24, n. 2, p. 141-160, 1988.

BISHKO, C. J. The Peninsular Background of Latin American Cattle Ranching. The Hispanic American Historical Review, v. 32, n. 4, p. 491-515, 1952.

BROWDER, J. O.; GODFREY, B. J. Rainforest Cities: Urbanization, Development, and Globalization of the Brazilian Amazon. New York: Columbia University Press, 1997. 458p.

BUTZER, K. Cattle and Sheep from Old to New Spain: Historical Antecedents. Annals of the Association of American Geographers, v. 78, n. 1, p. 29-56, 1988.

CLEARY, D. After the Frontier: Problems with Political Economy in the Modern Brazilian Amazon. Journal of Latin American Studies, v. 25, n. 2, p. 331-349, 1993.

COLSON, E. Native Cultural and Social Patterns in Contemporary Africa. In HAINES, C.G. Africa today. Baltimore: Johns Hopkins Press, 1955.

COMAROFF, J.; COMAROFF J. L. Goodly Beasts, Beastly Goods: Cattle and Commodities in the South African Context. American Ethnologist, v. 17, n. 2, p. 195-216, 1990.

DA CUNHA, E. Rebellion in the Backlands. Translated by Samuel Putnam. Chicago: University of Chicago Press, 1944. 532p.

DARY, D. Cowboy Culture. New York: Knopf, 1981. 400p.

DENT, A. S. River of Tears: Country Music, Memory, and Modernity in Brazil. Durham: Duke University Press, 2009. 312p.

DESCOLA, P. In the Society of Nature: A Native Ecology in Amazonia. Cambridge; New York: Cambridge University Press, 1994. 396p.

DESHLER, W. W. Native Cattle Keeping in Eastern Africa. In LEEDS, A.; VAYDA, A. P. Man, Culture, and Animals. Washington: AAAS, 1965.

DOVE, M.; CARPENTER, C. Environmental Anthropology: A Historical Reader. Oxford: Wiley-Blackwell, 2007. 480p.

DYSON-HUDSON, R.; DYSON-HUDSON, N. Nomadic Pastoralism. Annual Reviews of Anthropology, v. 9, p. 15-61, 1980.

ENSMINGER, J. Making a Market: The Institutional Transformation of an African Society. New York: Cambridge University Press, 1992. 230p.

EVANS-PRITCHARD, E. E. The Nuer. Oxford: Oxford University Press, 1940. 
FAO (Food and Agriculture Organization of the United Nations). Cattle Ranching and Deforestation (Livestock Policy Brief 03). Rome: FAO, 2006. Disponível em: ftp://ftp.fao.org/docrep/fao/010/a0262e/a0262e00.pdf. Acesso em: 19 abr. 2012.

FERGUSON, J. The Bovine Mystique: Power, Property, and Livestock. Rural Lesotho, v. 20, n. 4, p. 647-674, 1985.

FOWERAKER, J. The Struggle for Land. Cambridge, UK: University of Cambridge, 1981. 288p.

GALVIN, K. A. Transitions: Pastoralists Living with Change. Annual Review of Anthropology, 38, p. 185-198, 2009.

GOMES, C. V. Twenty years after Chico Mendes: Extractive Reserves' Expansion, Cattle Adoption and Evolving Self-Definition among Rubber Tappers in the Brazilian Amazon. Ph.D. dissertation, Department of Geography, University of Florida, 2009.

GONÇALVES, D. N.; IACOMINI, F. O Brasil Cowboy (The Brazilian Cowboy). Veja. 1997, August 27. Disponível em: http://veja.abril.com.br/270897/p_092.html. Acesso em: 15 jan. 2011.

HARRIS, M. The Cultural Ecology of India's Sacred Cow. Current Anthropology, v. 33, n. 1, p. 261-276, 1966.

HECHT, S. The Logic of Livestock and Deforestation in Amazonia. Bioscience, v. 43, n. 10, p. 687-695, 1993.

HECHT, S.; COCKBURN, A. The Fate of the Forest: Developers, Destroyers and Defenders of the Amazon. London: Verso, 1989. 406p.

HERSKOVITS, M. J. The Cattle Complex in East Africa. American Anthropologist, v. 28, n. 1, p. 230-272, 1926.

HOELLE, J. Convergence on Cattle: Political Ecology, Social Group Perceptions, and Socioeconomic Relationships in Acre, Brazil. Culture, Agriculture, Food and Environment, v. 33, n. 2, p. 95-106, 2011.

HUTCHINSON, S. Nuer Dilemmas: Coping with Money, War, and the State. Berkeley: University of California Press, 1996. 420P.

IBGE. Brazilian Institute of Statistics and Geography. Disponível em: http://www.ibge.gov.br/english. Acesso em: 01 jul. 2009.

INGOLD, T. Hunters, Pastoralists and Ranchers: Reindeer Economies and their Transformations. Cambridge: Cambridge University Press, 1980. 340P.

JORDAN, T. G. North American Cattle-ranching Frontiers: Origins, Diffusion, and Differentiation. Albuquerque: University of New Mexico Press, 1993. 456P.

KAIMOWITZ, D.; MERTENS, B.; WUNDER S.; PACHECO, P. Hamburger Connection Fuels Amazon Destruction. Bogor: CIFOR, 2004. 10p.

KECK, M. Social Equity and Environmental Politics in Brazil: Lessons from the Rubber Tappers of Acre. Comparative Politics, v. 27, n. 4, p. 409-424, 1995. 
KOTTAK, Conrad. Mirror for Humanity, sixth edition. Boston: McGraw Hill, 2008. 400p.

KAINER, K.; SCHMINK, M.; LEITE, A.C. P.; FADELL, M. J. S. Experiments in Forest- Based Development in the Western Amazon. Society and Natural Resources, v. 16, p. 869-886, 2003.

LAWRENCE. E. A. Rodeo Horses: The Wild and the Tame. In: WILLIS, R. Signifying Animals. London: Unwin Hyman, 1990.

LEA, T. The King Ranch. 1. ed. Boston: Little and Brown, 1957. 838p.

LOKER, W. The Human Ecology of Cattle Raising in the Peruvian Amazon-The View from the Farm. Human Organization, v. 52, n. 1, p. 14-24, 1993.

MARTINELlO, P. A Batalha da Borracha na Segunda Guerra Mundial. Rio Branco, Brazil: EDUFAC, 2004.

MARX, K. Capital. Vol. I. New York: Random House/Vintage, 1977. 894p.

MAZZA, C.; MAZZA, C.; SERENO, J.; SANTOS, S.; PELlEGRIN, A. Etnobiologia e Conservação do Bovino Pantaneiro. Brasília: Embrapa, 1994. 61p.

McCABE, T. Cattle Bring Us to Our Enemies: Turkana Ecology, History, and Raiding in a Disequilibrium System. Ann Arbor: University of Michigan Press, 2004. 320p.

MEILLASSOUX, C. From Reproduction and Production: A Marxist Approach to Economic Anthropology. In: WOLPE, H. The Articulation of Modes of Production. London: Routledge, 1980.

MILLER, B. Cultural Anthropology in a Globalizing World. 2. ed. Pearson Press: Boston, 2008. $336 \mathrm{p}$.

MOORE, S. F. Changing Perspectives on a Changing Africa: The Work of Anthropology. In: BATES, R.; MUDIMBE V. Y.; O'BARR, J. Africa and the disciplines. Chicago: University of Chicago Press, 1993.

MORAN, E. Developing the Amazon. Bloomington: Indiana University Press, 1981. 292p.

MORTIZ, M.; RITCHEY, K.; KARI, S. The Social Context of Herding Contracts in the Far North Region of Cameroon. The Journal of Modern African Studies, v. 49, n. 2, p. 263-285, 2011.

OLIVEN, R. G. The Largest Popular Culture Movement in the Western World: Intellectuals and Gaúcho Traditionalism in Brazil. American Ethnologist, v. 27, n. 1, p. 128-146, 2000.

PACHECO, P.; POCCARD-CHAPUIS, R. The Complex Evolution of Cattle Ranching Development Amid Market Integration and Policy Shifts in the Brazilian Amazon. Annals of the Association of American Geographers, v. 102, n. 6, p. 1366-1390, 2012.

RIFKIN, J. Beyond Beef: The Rise and Fall of the Cattle Culture. New York: Plume, 1993. 368p.

RIMAS, A.; FRASER, E. Beef: The Untold Story of how Milk, Meat and Muscle Shaped the World. New York: Harper Collins, 2008. 256p. 
RIVIÈRE, P. The Forgotten Frontier: Ranchers of North Brazil. New York: Holt, Rinehart and Winston, 1972. 127p.

ROSEBERRY, W. Anthropologies and Histories: Essays in Culture, History and Political Economy. New Brunswick: Rutgers University Press, 1989. 296p.

RUDEL, T. K.; BATES, D.; MACHINGUIASHI, R. Ecologically Noble Amerindians? Cattle Ranching and Cash Cropping among Shuar and Colonists in Ecuador. Latin American Research Review, v. 37, n. 1, p. 144-159, 2002.

SAHLINS, M. Stone Age Economics. New York: Aldine de Gruyter, 1972. 348p.

SALISBURY, D.; SCHMINK, M. Cows versus Rubber: Changing Livelihoods among Amazonian Extractivists. Geoforum, v. 38, n. 6, p. 1233-1249, 2007.

SCHMINK, M. Forest Citizens: Changing Life Conditions and Social Identities in the Land of the Rubber Tappers. Latin American Research Review, v. 46, p. 141-158, 2011.

SCHMINK, M.; CORDEIRO, M. L. Rio Branco: A Cidade da Florestania. Belém: Universidade Federal do Pará, 2008. 185p.

SCHMINK, M.; WOOD, C. Contested Frontiers in Amazonia. New York: Columbia University Press, 1992. 387p.

SCHNEIDER, H. K. The Subsistence Role of Cattle among the Pakot and in East Africa. American Anthropologist, v. 59, n. 2, p. 278-300, 1957.

SLATTA, R. Cowboys of the Americas. New Haven: Yale University, 1990. 168p.

SMERALDI, R.; MAY, P. O Reino do Gado: uma nova fase na pecuarização da Amazônia. São Paulo: Amigos da Terra, 2008. 39p.

STOELtJE, B. Rodeo: From Custom to Ritual. Western Folklore, v. 48, n. 3, p. 244-255, 1989.

STRICKON, A. The Euro-American Ranching Complex. In: LEEDS, A.; VAYDA, A. P. Man, Culture, and Animals. Washington: AAAS, 1965.

TINKER, E. L. Life and Literature in the Pampas. Gainesville: University of Florida Press, 1961. $62 \mathrm{p}$.

VADJUNEC, J.; SCHMINK, M.; GREINER, A. L. New Amazonian Geographies: Emerging Identities and Landscapes. Journal of Cultural Geography, v. 28, n. 1, p. 1-20, 2011.

VIVEIROS DE CASTRO, E. Cosmological Deixis and Amerindian Perspectivism. Journal of the Royal Anthropological Institute, v. 4, n. 3, p. 469-488, 1998.

WALKER, R.; BROWDER, J.; ARIMA, E.; SIMMONS, C.; PEREIRA, R.; CALDAS, M.; SHIROTA, R.; ZEN, S. Ranching and the New Global Range: Amazonia in the $21^{\text {st }}$ Century. Geoforum, v. 40, p. 732-745, 2009.

WEINSTEIN, B. The Amazon Rubber Boom, 1850-1920. Stanford: Stanford University Press, 1983. 356p. 
WOLF, E. Europe and the People without History. Berkeley: University of California Press, 1982. 534p.

WOLPE, H. The Articulation of Modes of Production. London: Routledge, 1980. 